\title{
Comparison study for surgical outcomes of right versus left side hemihepatectomy to treat hilar cholangiocellular carcinoma
}

\author{
Seung Soo Hong ${ }^{1}$, Dai Hoon Han ${ }^{1,2}$, Gi Hong Choi ${ }^{1,2}$, Jin Sub Choi ${ }^{1,2}$ \\ ${ }^{1}$ Department of Surgery, Yonsei University College of Medicine, Seoul, Korea \\ 'Yonsei Liver Cancer Special Clinic, Yonsei University College of Medicine, Seoul, Korea
}

\begin{abstract}
Purpose: Major liver resection and radical lymph node dissection has been accepted as a definite treatment of choice for hilar cholangiocarcinoma $(\mathrm{HC})$. However, the perioperative and survival outcomes of right hemihepatectomy $(\mathrm{RH})$ and left hemihepatectomy (LH) still remain controversial. Thus, this study aimed to compare the surgical and oncological outcomes of $\mathrm{RH}$ and $\mathrm{LH}$ in $\mathrm{HC}$ patients.

Methods: From January 2000 to January 2018, a total of 326 patients underwent surgical resection for HC at Yonsei University College of Medicine in Seoul, Korea. Among the 326 patients, we excluded 130 patients and selected 196 patients, who underwent hemihepatectomy with caudate lobectomy. Among these 196 patients, 114 patients underwent $\mathrm{RH}$, and 82 patients underwent $\mathrm{LH}$. We compared the clinicopathological features as well as the surgical and oncologic outcomes of the RH and LH groups.

Results: There were no significant differences in disease-free survival $(P=0.473)$ or overall survival $(P=0.946)$ in the $R H$ and LH groups. The LH group had fewer complications compared with the RH group, including postoperative ascites (RH: 15 [13.2\%] vs. LH: 3 [3.7\%], P = 0.023); however, the LH group had more bile leakage complications (RH: 5 [4.4\%] vs. LH: 12 [14.6\%], $P=0.012$ ). The average time lag from portal vein embolization to operation was $25.80 \pm 12.06$ days $(n=45)$. There was no difference in postoperative liver failure $(P=0.402)$, although there were significantly more frequent ascites after $R H$ $(P=0.023)$.

Conclusion: LH might be a good alternative option for the surgical treatment of HC given appropriate tumor location and biliary anatomy indications.
\end{abstract}

[Ann Surg Treat Res 2020;98(1):15-22]

Key Words: Hepatectomy, Klatskin tumor, Treatment outcome

\section{INTRODUCTION}

The major liver resection with caudate lobectomy and radical lymph node (LN) dissection has been accepted as a definite treatment of choice for hilar cholangiocarcinoma (HC) [1-8]. In terms of major liver resection procedures, right hemihepatectomy $(\mathrm{RH})$ has usually been selected for two- thirds of patients treated for HC [9-11]. Radical removal of the caudate lobe as well as relatively easy biliary reconstruction was the main reason to perform RH [9]. However, as more than $60 \%$ of the total liver volume should be removed by $\mathrm{RH}$, the patient might be confronted with a high risk of postoperative liver failure (PLF) [12,13]. Although left hemihepatectomy (LH) could be considered a treatment option for HC, LH might be
Received August 13, 2019, Revised October 12, 2019,

Accepted October 31, 2019

Corresponding Author: Dai Hoon Han

Department of Surgery, Yonsei University College of Medicine, 50

Yonsei-ro, Seodaemoon-gu, Seoul 03722, Korea

Tel: +82-2-2228-2099, Fax: +82-2-313-8289

E-mail: dhhan@yuhs.ac

ORCID: https://orcid.org/0000-0003-2787-7876
Copyright (c) 2020, the Korean Surgical Society

(c) Annals of Surgical Treatment and Research is an Open Access Journal. All articles are distributed under the terms of the Creative Commons Attribution NonCommercial License (http://creativecommons.org/licenses/by-nc/4.0/) which permits unrestricted non-commercial use, distribution, and reproduction in any medium, provided the original work is properly cited. 
technically demanding due to the difficult anastomosis from the multiple openings of the right hepatic ducts and posterior hepatic duct located posterior to the right portal vein (RPV) [14]. Moreover, the bifurcation of biliary confluences usually located in the right vascular structures and the relatively long left hepatic duct compared with the right hepatic duct may make it possible that $\mathrm{RH}$ has a greater chance of $\mathrm{R} 0$ resection [15]. However, perioperative outcomes and survival data for $\mathrm{RH}$ and LH still remain controversial. Thus, this study aimed to compare the surgical and oncological outcomes of $\mathrm{RH}$ and $\mathrm{LH}$ in $\mathrm{HC}$ patients.

\section{METHODS}

\section{Patients and subgroup analysis}

From January 2000 to December 2018, a total of 326 consecutive patients underwent surgical treatment for $\mathrm{HC}$ at Yonsei University College of Medicine in Seoul, Korea. Surgical treatment was defined as a surgical approach in patients diagnosed with HC, including not only liver resection, but also bile duct resection, palliative surgery, even opening and closure $(\mathrm{n}=326)$. Among these 326 patients, 196 patients having $\mathrm{RH}$ or LH with caudate lobectomy and Roux-en-Y hepaticojejunostomy were included in the study, and we compared the clinicopathologic features, surgical outcomes, and oncologic outcomes between the RH and LH groups. In terms of Bismuth types II and IV, as surgeons might choose the operative option as $\mathrm{RH}$ or $\mathrm{LH}$, we compared the $\mathrm{RH}(\mathrm{n}=35)$ and $\mathrm{LH}(\mathrm{n}=$ 34) groups of patients diagnosed as Bismuth type II or type IV HC. Portal vein embolization (PVE) could be the cause of a time lag between diagnosis and operation. Thus, we also compared the RH following PVE group $(n=45)$ and the LH group $(n=82)$
(Fig. 1).

This retrospective cohort study was approved by the Institutional Review Board of Severance Hospital, Yonsei University Health System (4-2018-0802) and exempted from the informed consent.

\section{Analysis of patient characteristics, surgical outcomes, and oncologic outcomes}

In determining right and LH, we considered margin, vessel invasion, and future remnant liver volume. If we could get the negative margin in bifurcation level of right anterior and posterior bile duct (U-point) based on preoperative radiology, we planned LH. On the contrary, if we could not get the negative margin of U-point in the presence of cancer invasion, we considered $\mathrm{RH}$ after confirming the negative margin of left trifurcation level of B2, B3, and B4. In case of possible obtaining negative margin in both bile ducts, we considered vessel invasion and future remnant liver volume. In presence of portal vein or hepatic artery invasion, we conducted hemihepatectomy of corresponding lobe. In case of Bismuth type 2 or type 4 Klatskin tumor, we conducted LH when future remnant liver volume is considered not sufficient to maintain liver function.

In the comparison study of RH and LH, and 2 subgroup analyses, we analyzed patient characteristics, surgical outcomes, and oncologic outcomes. Patient characteristics included age, sex, preoperative lab findings (albumin, AST/ALT, gamma-glutamyl transpeptidase [GGT], CA 19-9, CEA, total bilirubin, and highest total bilirubin), preoperative procedures (biliary drainage and PVE), Bismuth type, and stage. Surgical outcomes included surgical complications (ascites, postoperative bleeding, bile leakage, sepsis, pleural effusion, abscess, wound infection, liver failure, and postoperative mortality) and operative findings

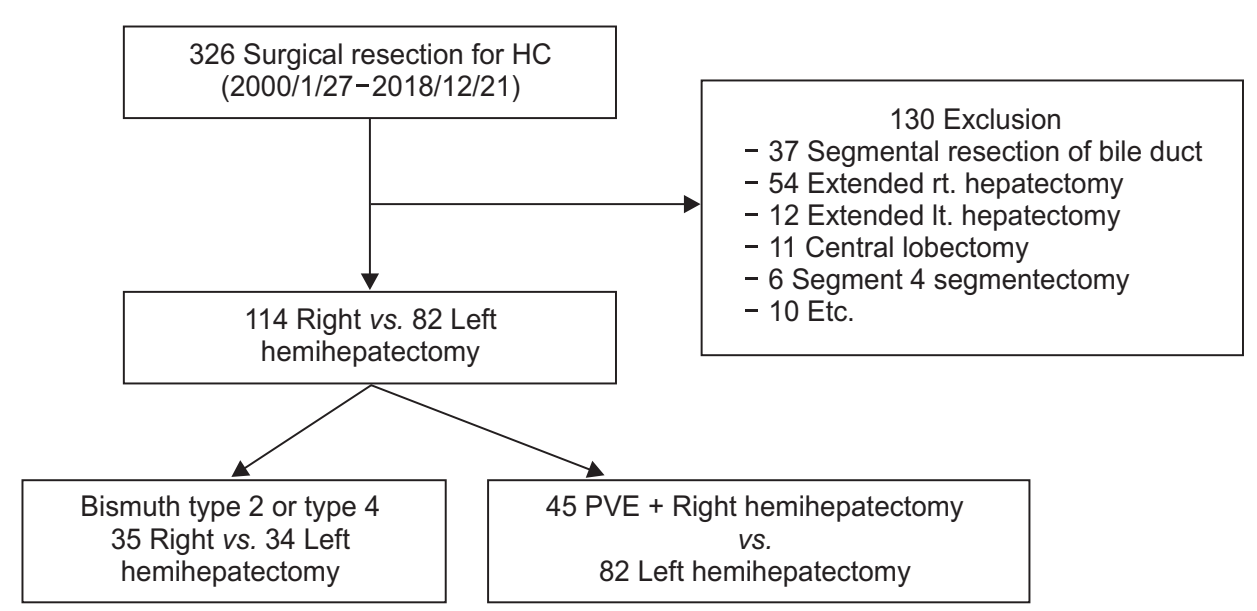

Fig. 1. Classification of patients for the study. Among 326 total patients diagnosed as hilar cholangiocarcinoma (HC), 130 patients were excluded; the remaining patients were then divided into 2 groups of right hemihepatectomy $(\mathrm{RH})$ patients $(\mathrm{n}=$ 114) and left hemihepatectomy $(\mathrm{LH})$ patients $(\mathrm{n}=82)$. In one subgroup analysis, we compared RH patients of Bismuth type II or type IV $(\mathrm{n}=35)$ and LH patients, and in another subgroup analysis, we also compared patients who underwent portal vein embolization (PVE) followed by RH $(n=45)$ and $\mathrm{LH}(\mathrm{n}=82)$ patients. 
(intraoperative bleeding, transfusion, R0 resection rate, and operation time). Oncologic outcomes were also analyzed including local recurrence, systemic recurrence, overall survival
(OS), and disease-free survival (DFS). PLF was defined as PT $<$ $50 \%$ and total bilirubin $>50 \mu \mathrm{mol} / \mathrm{L}(>2.92 \mathrm{mg} / \mathrm{dL})$ according to the rule of "50-50 criteria," which predicts the possibility of

Table 1. Patient characteristics of RH vs. LH groups

\begin{tabular}{|c|c|c|c|}
\hline Variable & $\mathrm{RH}(\mathrm{n}=114)$ & $\mathrm{LH}(\mathrm{n}=82)$ & P-value \\
\hline Age $(y r)$ & $63.64 \pm 8.72$ & $63.46 \pm 10.38$ & 0.897 \\
\hline Sex, male:female & $76: 38(66.7: 33.3)$ & $56: 26(68.3: 31.7)$ & 0.811 \\
\hline Albumin (g/dL) & $3.52 \pm 0.42$ & $3.63 \pm 0.47$ & 0.084 \\
\hline AST (IU/L) & $43.35 \pm 25.15$ & $45.65 \pm 29.92$ & 0.561 \\
\hline $\operatorname{ALT}(\mathrm{IU} / \mathrm{L})$ & $47.49 \pm 58.05$ & $44.38 \pm 50.50$ & 0.696 \\
\hline ALP (IU/L) & $252.04 \pm 203.24$ & $226.28 \pm 166.61$ & 0.349 \\
\hline GGT (IU/L) & $413.29 \pm 436.91$ & $455.74 \pm 521.34$ & 0.550 \\
\hline CA 19-9 (U/mL) & $1,054.27 \pm 3,491.50$ & $943.74 \pm 1,863.80$ & 0.796 \\
\hline $\mathrm{CEA}(\mathrm{ng} / \mathrm{mL})$ & $3.95 \pm 7.63$ & $8.57 \pm 41.29$ & 0.335 \\
\hline Preop T.Bil (mg/dL) & $1.61 \pm 1.18$ & $1.61 \pm 1.22$ & 0.968 \\
\hline Preop highest T.Bil (mg/dL) & $7.99 \pm 7.06$ & $6.32 \pm 5.93$ & 0.083 \\
\hline Cholangitis (T.Bil $\geq 2$ ) & $86(75.4)$ & $54(65.9)$ & 0.143 \\
\hline Preop biliary drainage & $93(60.8)$ & $60(73.2)$ & 0.161 \\
\hline Portal vein embolization & $45(39.5)$ & $2(2.4)$ & $<0.001^{*}$ \\
\hline Portal vein resection & $8(7.0)$ & $4(4.9)$ & 0.538 \\
\hline \multicolumn{4}{|l|}{ Bismuth type } \\
\hline Type I & $4(3.5)$ & $5(6.1)$ & \\
\hline Type II & $13(11.4)$ & $6(7.3)$ & \\
\hline Type IIIa or IIIb & $75(65.8)$ & $43(52.5)$ & \\
\hline Type IV & $22(19.3)$ & $28(34.1)$ & \\
\hline
\end{tabular}

Values are presented as mean \pm standard deviation or number $(\%)$.

$\mathrm{RH}$, right hemihepatectomy; LH, left hemihepatectomy; GGT, gamma-glutamyl transpeptidase; Preop, preoperative; T.Bil, total bilirubin.

$* P<0.05$ statistically significant differences.

Table 2. Perioperative outcomes of RH vs. LH

\begin{tabular}{lccc}
\hline Perioperative outcome & $\mathrm{RH}(\mathrm{n}=114)$ & $\mathrm{LH}(\mathrm{n}=82)$ & P-value \\
\hline Intraoperative findings & & & 0.655 \\
Intraoperative bleeding $(\mathrm{mL})$ & $1,179.82 \pm 1,195.35$ & $1,262.56 \pm 1,384.15$ & 0.087 \\
Transfusion & $43(37.7)$ & $41(50.0)$ & 0.538 \\
Portal vein resection & $8(7.0)$ & $6(7.9)$ & $0.022^{*}$ \\
Hepatic artery resection & $1(0.9)$ & $62(75.6)$ & 0.659 \\
R0 resection rate & $83(72.8)$ & $551.07 \pm 181.68$ & 0.178 \\
Operation time (min) & $517.80 \pm 161.24$ & $3(3.7)$ & 0.156 \\
Postoperative mortality & $10(8.8)$ & $3(3.7)$ & $0.023^{*}$ \\
Postoperative findings & $15(13.2)$ & $2(2.4)$ & $>0.999$ \\
Ascites & $4(3.5)$ & $12(14.6)$ & $0.012^{*}$ \\
Postoperative bleeding & $5(4.4)$ & $3(3.7)$ & $>0.999$ \\
Bile leakage & $5(4.4)$ & $7(8.5)$ & 0.790 \\
Sepsis & $11(9.6)$ & $7(8.5)$ & 0.871 \\
Pleural effusion & $9(7.9)$ & $1(1.2)$ & 0.402 \\
Wound infection & $4(3.5)$ & $41(50.0)$ & 0.808 \\
Liver failure & $59(51.8)$ & & \\
Overall complication & & & \\
\hline
\end{tabular}

Values are presented as mean \pm standard deviation or number (\%).

$\mathrm{RH}$, right hemihepatectomy; $\mathrm{LH}$, left hemihepatectomy.

$* \mathrm{P}<0.05$ statistically significant differences. 
liver failure after hemihepatectomy [16]. Finally, we analyzed patients' characteristics affecting recurrence and survival using univariate and multivariate analysis.

A

$\mathrm{RH}(\mathrm{n}=114)$ vs. LH $(\mathrm{n}=82)$

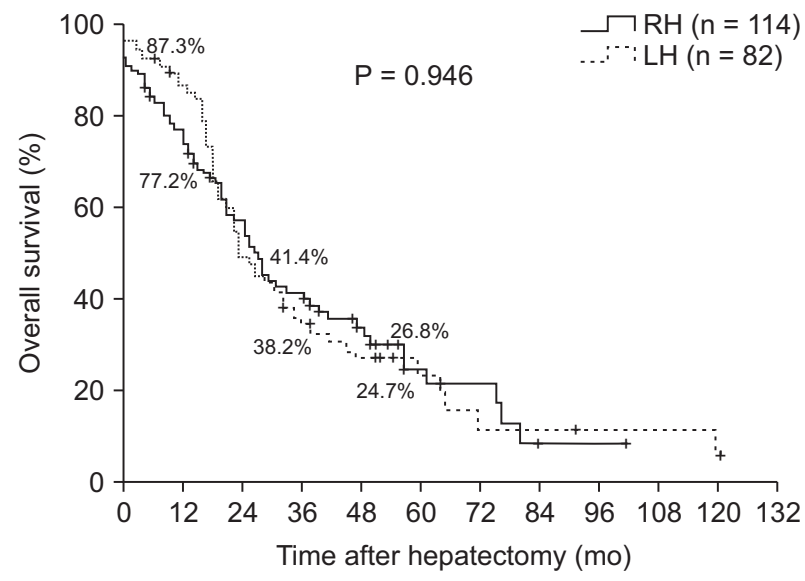

C

Bismuth type 2 or $4 \mathrm{RH}(\mathrm{n}=35)$ vs. LH $(\mathrm{n}=34)$

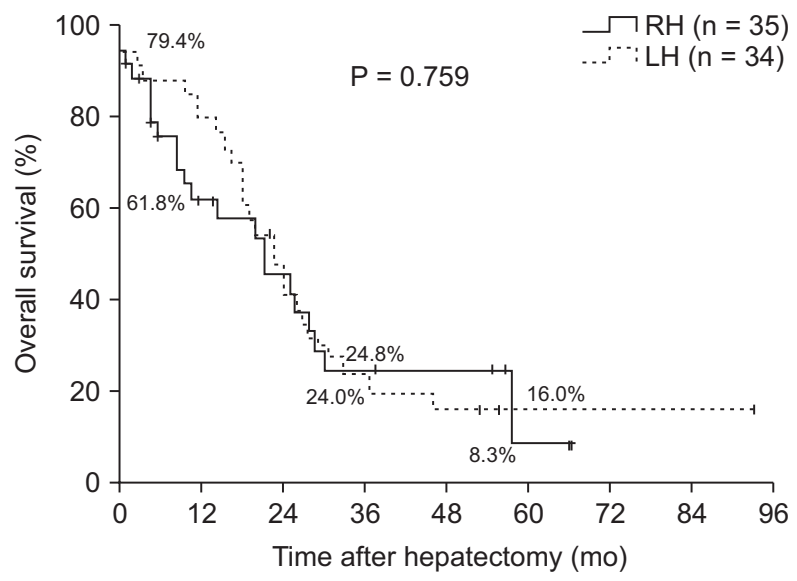

E

PVE + RH $(n=45)$ vs. LH $(n=82)$

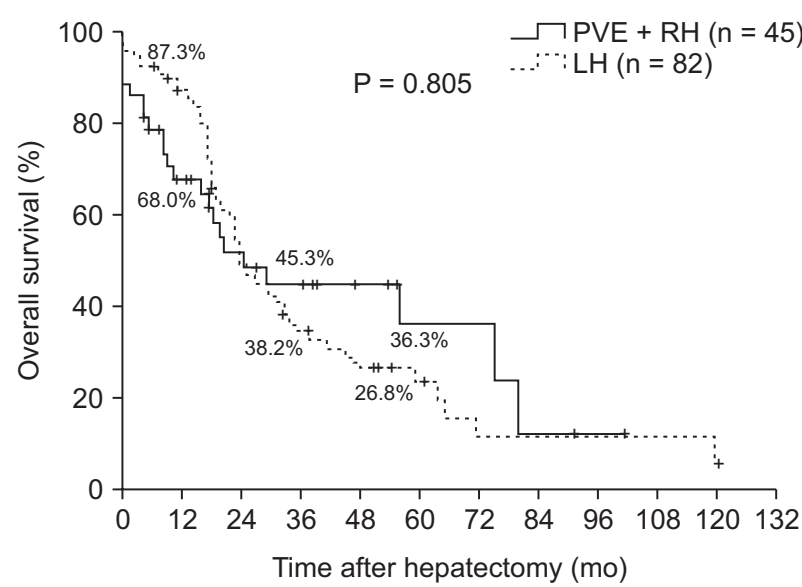

\section{Statistical analysis}

Categorical variables were compared with $\chi^{2}$ or Fisher exact tests, as appropriate. Survival curves were obtained by the

B

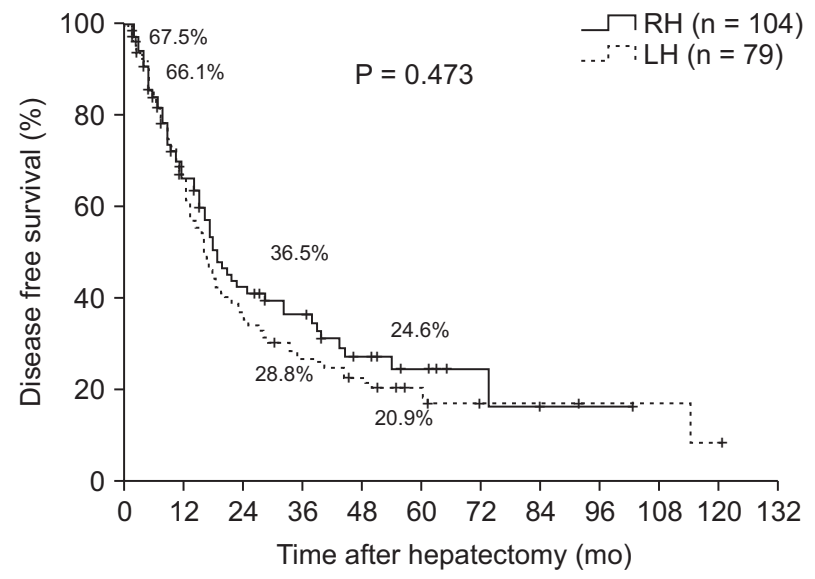

D Bismuth type 2 or $4 \mathrm{RH}(\mathrm{n}=31)$ vs. $\mathrm{LH}(\mathrm{n}=32)$

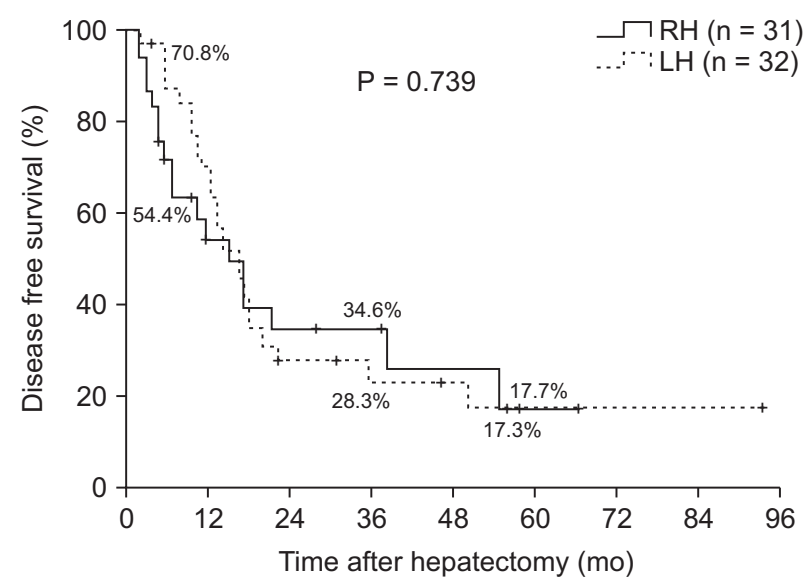

F $\quad \mathrm{PVE}+\mathrm{RH}(\mathrm{n}=39)$ vs. LH $(\mathrm{n}=79)$

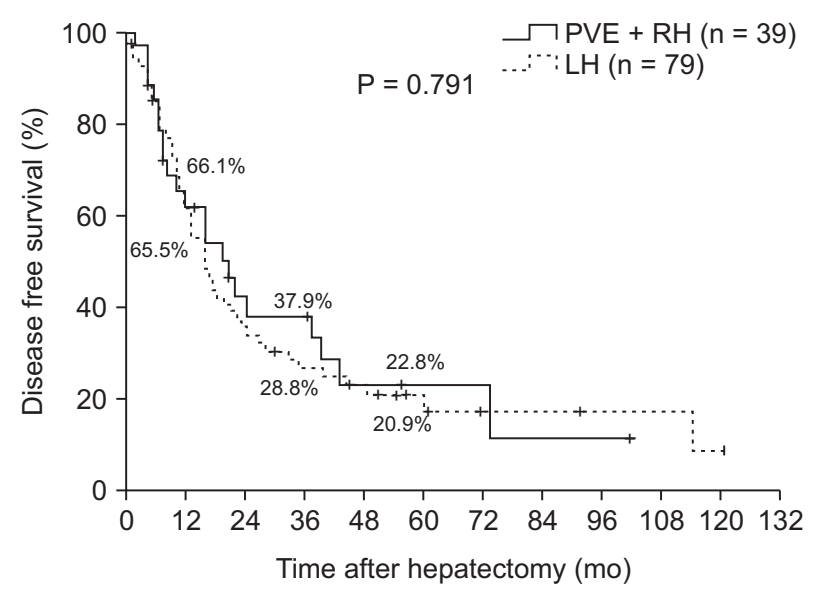

Fig. 2. (A, B) Disease-free and overall survival rates in RH vs. LH groups. In subgroup analysis, disease-free and overall survival rates in RH of Bismuth type II or IV patients and in LH patients (C, D), and in PVE + RH and LH patients (E, F). PVE, portal vein embolization; RH, right hemihepatectomy; LH, left hemihepatectomy. 
Kaplan-Meier method, and differences in survival between groups were compared with the log-rank test. Perioperative mortalities were included in the OS analysis but excluded from the DFS analysis. Finally, we used the Kaplan-Meier method and Cox regression test for analyzing patients' characteristics affecting recurrence and survival. Statistical analyses were performed with IBM SPSS Statistics ver. 23.0 (IBM Co., Armonk, NY, USA). A P-value less than 0.05 was considered statistically significant.

\section{RESULTS}

\section{Right versus left lobectomy}

We compared preoperative characteristics as well as surgical and oncologic outcomes of $114 \mathrm{RH}$ and $82 \mathrm{LH}$ patients. In

Table 3. Independent prognostic factors for disease-free and overall survival by multivariate analysis

\begin{tabular}{ccccc}
\hline Variable & $\begin{array}{c}\text { Coef- } \\
\text { ficient }\end{array}$ & $\begin{array}{c}\text { Stan- } \\
\text { dard } \\
\text { error }\end{array}$ & P-value & $\begin{array}{c}\text { Relative risk } \\
(95 \% \mathrm{Cl})\end{array}$ \\
\hline $\begin{array}{c}\text { DFS } \\
\text { CA 19-9 } \\
\text { over 400 } \\
\text { Lymph node } \\
\text { metastasis }\end{array}$ & 0.483 & 0.195 & 0.013 & $1.621(1.107-2.374)$ \\
$\begin{array}{c}\text { OVS } \\
\text { CA 19-9 } \\
\text { over 400 }\end{array}$ & 0.651 & 0.203 & 0.001 & $1.918(1.288-2.855)$ \\
\hline
\end{tabular}

$\mathrm{Cl}$, confidence interval; DFS, disease-free survival; OVS, overall survival. preoperative characteristics, we compared the mean values of age, preoperative albumin, AST/ALT, ALP, GGT, CA 19-9, CEA, preoperative total bilirubin, and preoperative highest total bilirubin and also compared the ratio of male/female, preoperative biliary drainage, PVE, and portal vein resection. There were no significant differences between the 2 groups in disease severity in preoperative lab findings, or in the proportions of preoperative biliary drainage and portal vein resection (Table 1). In surgical outcomes, the complications between the 2 groups had differences in ascites, with many more occurrences of ascites in $\mathrm{RH}$ patients (15 patients, 13.2\%) compared with LH patients ( 3 patients, 3.7\%) $(\mathrm{P}=0.023)$, whereas $\mathrm{LH}$ patients had more bile leakage than $\mathrm{RH}$ patients, with 12 patients (14.6\%) and 5 patients (4.4\%), respectively ( $\mathrm{P}=$ 0.012). Intraoperative surgical outcomes had no significant differences between the 2 groups including intraoperative bleeding, transfusion rate, $\mathrm{R} 0$ resection rate, operation time, and postoperative mortality (Table 2). In oncologic outcomes, we analyzed the DFS and OS between the 2 groups. The 1-, 3-, and 5-year DFS rates of the RH group were $66.1 \%, 36.5 \%$, and $24.6 \%$, and those of the LH group were $67.1 \%, 28.8 \%$, and $20.9 \%$, respectively. In OS, the 1-, 3- and 5-year survival rates of the RH group were $77.2 \%, 41.4 \%$, and $26.8 \%$, and those of the LH group were $87.3 \%, 38.2 \%$, and $24.7 \%$, respectively. In both DFS and OS, there were no significant differences between the 2 groups $(\mathrm{P}=$ 0.473 and $\mathrm{P}=0.946$, respectively) (Fig. 2). In univariate analyses of patients' characteristics affecting DFS and OVS, preoperative AST $>50 \mathrm{IU} / \mathrm{L}$, preoperative CA $19-9>400 \mathrm{U} / \mathrm{mL}$, and LN metastasis were negative prognostic factors for DFS $(\mathrm{P}=0.014$, $\mathrm{P}=0.001$, and $\mathrm{P}=0.016$, respectively), and preoperative serum albumin $\leq 3.5 \mathrm{~g} / \mathrm{dL}$ and preoperative CA $19-9>400 \mathrm{U} / \mathrm{mL}$ were

Table 4. Perioperative outcomes in Bismuth type II or IV RH vs. LH

\begin{tabular}{lccc}
\hline Perioperative outcome & RH $(\mathrm{n}=35)$ & $\mathrm{LH}(\mathrm{n}=34)$ & P-value \\
\hline Intraoperative findings & & & \\
Intraoperative bleeding $(\mathrm{mL})$ & $1,448.29 \pm 1,669.33$ & $22(64.7)$ & 0.761 \\
Transfusion & $12(34.3)$ & $26(76.5)$ & $0.012^{*}$ \\
R0 resection rate & $24(68.6)$ & $564.00 \pm 160.27$ & 0.463 \\
Operation time (min) & $490.91 \pm 127.07$ & $2(5.9)$ & $0.039^{*}$ \\
Postoperative mortality & $4(11.4)$ & $1(2.9)$ & 0.198 \\
Postoperative findings & $5(14.3)$ & $2(5.9)$ & 0.614 \\
Ascites & $1(2.9)$ & $6(17.6)$ & $0.011^{*}$ \\
Postoperative bleeding & $0(0.0)$ & $1(2.9)$ & 0.614 \\
Bile leakage & $3(8.6)$ & $3(8.8)$ & $>0.999$ \\
Sepsis & $4(11.4)$ & $5(14.7)$ & 0.477 \\
Pleural effusion & $3(8.6)$ & $1(2.9)$ & $>0.999$ \\
Wound infection & $2(5.7)$ & $19(55.9)$ & 0.916 \\
Liver failure & $20(57.1)$ & & \\
Overall complications & & \\
\hline
\end{tabular}

Values are presented as mean \pm standard deviation or number (\%).

$\mathrm{RH}$, right hemihepatectomy; $\mathrm{LH}$, left hemihepatectomy.

$* \mathrm{P}<0.05$ statistically significant differences. 
negative prognostic factors for OS $(\mathrm{P}=0.028, \mathrm{P}=0.044$, and $\mathrm{P}=0.004$, respectively). In multivariate analyses, we concluded that preoperative CA $19-9>400 \mathrm{U} / \mathrm{mL}$ and $\mathrm{LN}$ metastasis were independent prognostic factors for DFS (odds ratio, 2.043; $\mathrm{P}=$ 0.001 and odds ratio, 1.621; $\mathrm{P}=0.013$, respectively), and for OS, CA $19-9>400 \mathrm{U} / \mathrm{mL}$ was an independent prognostic factor (odds ratio, 1.702; $\mathrm{P}=0.009$ and odds ratio, 1.918; $\mathrm{P}=0.001$, respectively) (Table 3).

\section{Right versus left lobectomy in Bismuth types II and IV}

Among $114 \mathrm{RH}$ patients and $82 \mathrm{LH}$ patients, we selected Bismuth type II or type IV patients diagnosed in preoperative evaluations ( $35 \mathrm{RH}$ and $34 \mathrm{LH}$ patients). For these patients, we also analyzed preoperative characteristics as well as surgical and oncologic outcomes. Between the 2 subgroups, there were no significant differences in disease severity or preoperative lab findings. The surgical outcomes of the 2 subgroups had a significant difference in the proportion of bile leakage. The $\mathrm{LH}$ subgroup had significantly more frequent occurrence of bile leakage (RH: 0 [0\%] vs. LH: $6[17.6 \%], \mathrm{P}=0.011$ ). Although the P-value was not significant, the RH subgroup had a tendency toward more frequent occurrence of ascites and liver failure. In perioperative surgical outcomes, the LH subgroup had more transfusions (RH: 12 patients [34.3\%] vs. LH: 22 patients [64.7\%], $\mathrm{P}=0.012$ ), and required more operation time (RH: $490.91 \pm$ 127.07 minutes vs. LH: $564.00 \pm 160.27$ minutes, $P=0.039$ ) (Table 4). Oncologic outcomes were not different between the 2 subgroups; in a comparison of OS and DFS, the 2 subgroups were not different (OS, $\mathrm{P}=0.759$; $\mathrm{DFS}, \mathrm{P}=0.739$ ) (Fig. 2).
Right lobectomy after PVE versus left lobectomy

We conducted another subgroup analysis to evaluate the effects of LH on survival compared to PVE followed by RH. Among $114 \mathrm{RH}$ patients, we selected 45 patients who underwent PVE followed by RH and compared them with 82 patients who underwent $\mathrm{LH}$ alone. The methods of analysis were the same as above. Like the 2-subgroup analysis above, the PVE + RH and LH groups had no differences in patients' characteristics. Also, the PVE + RH group had significantly more ascites $(\mathrm{PVE}+\mathrm{RH}$ : 11 patients [24.4\%] vs. LH: 3 patients [3.7\%], $\mathrm{P}=0.001$ ), whereas the LH group had more bile leakage (PVE + RH: 1 patient [2.2\%] vs. LH: 12 patients [14.6\%], $\mathrm{P}=0.032$ ). The 2 subgroups also had no significant differences in perioperative surgical outcomes (Table 5). Likewise, there were no significant differences between the 2 subgroups in oncologic outcomes, OS, or DFS (Fig. 2). The average time lag from PVE to operation was $25.80 \pm$ 12.06 days $(n=45)$.

\section{DISCUSSION}

Major liver resection with radical LN dissection is the treatment of choice for HC curative treatment. However, anatomically, the distance from the primary biliary bifurcation to the sectional branch in the right liver is much shorter than that in the left, and right sectional bile ducts have many anatomical variations [17]. For these reasons, many surgeons have preferred the right-side hemihepatectomy to the left despite the lesser remnant liver volume [11]. Generally, it is known that two-thirds of liver volume is found in the right lobe and one-third is in the left lobe. Previous studies reported average proportions of right, left, and caudate lobes as $67 \%, 31 \%$,

Table 5. Perioperative outcomes of PVE + RH vs. LH

\begin{tabular}{lccc}
\hline Perioperative outcome & RH $(\mathrm{n}=45)$ & LH $(\mathrm{n}=82)$ & P-value \\
\hline Intraoperative findings & & & \\
Intraoperative bleeding $(\mathrm{mL})$ & $1,279.11 \pm 1,377.86$ & $1,262.56 \pm 1,384.15$ & 0.949 \\
Transfusion & $15(33.3)$ & $62(75.6)$ & 0.070 \\
Ro resection rate & $35(77.8)$ & $551.07 \pm 181.68$ & 0.783 \\
Operation time (min) & $492.67 \pm 158.04$ & $3(3.7)$ & 0.072 \\
Postoperative mortality & $6(13.3)$ & $3(3.7)$ & 0.067 \\
Postoperative findings & $11(24.4)$ & $2(2.4)$ & $0.001^{*}$ \\
Ascites & $2(4.4)$ & $12(14.6)$ & 0.614 \\
Postoperative bleeding & $1(2.2)$ & $3(3.7)$ & $0.032^{*}$ \\
Bile leakage & $4(8.9)$ & $7(8.5)$ & 0.244 \\
Sepsis & $2(4.4)$ & $7(8.5)$ & 0.490 \\
Pleural effusion & $4(8.9)$ & $1(1.2)$ & 0.999 \\
Wound infection & $3(6.7)$ & $41(50.0)$ & 0.186 \\
Liver failure & $28(62.2)$ & \\
Overall complications & & \\
\hline
\end{tabular}

Values are presented as mean \pm standard deviation or number $(\%)$.

$\mathrm{PVE}$, portal vein embolization; $\mathrm{RH}$, right hemihepatectomy; $\mathrm{LH}$, left hemihepatectomy.

$* \mathrm{P}<0.05$ statistically significant differences. 
Table 6. Cause of mortality

\begin{tabular}{lcc}
\hline \multicolumn{1}{c}{ Cause of mortality } & $\begin{array}{c}\text { Right } \\
\text { hepatectomy } \\
(\mathrm{n}=114)\end{array}$ & $\begin{array}{c}\text { Left hepatec- } \\
\text { tomy } \\
(\mathrm{n}=82)\end{array}$ \\
\hline Aspiration pneumonia & 1 & 1 \\
Septic shock & 3 & - \\
Postoperative liver failure & 3 & 2 \\
Postoperative bleeding & 3 & - \\
Postoperative mortality, $\mathrm{n}(\%)$ & $10(8.8)$ & $3(3.7)$ \\
\hline
\end{tabular}

and $2 \%$, respectively [12]. These anatomical issues have caused higher perioperative mortality and complications such as PLF or cholangitis in RH. PVE is generally used to secure sufficient right liver volume [18,19]; however, it could be the cause of time lag until the operation. The average time lag between PVE and operation was $25.80 \pm 12.06$ days $(n=45)$ in our data.

In this study, the LH group had significantly fewer ascites without significant differences in the bleeding rates, R0 resectability, or recurrence patterns. Oncologically, LH was not inferior to RH in DFS and OS. In subgroup analysis of PVE followed by RH compared to LH, LH also had the advantages of fewer ascites and shorter time intervals between diagnosis and radical operation (Table 6). These results show that if the tumor's location is such that it can be removed by LH, then LH can be a good alternative option for reducing perioperative morbidity and mortality by preserving remnant liver volume.

Some authors reported that right resections still cause significant morbidity related to extensive parenchymal sacrifice, but they are associated with better long-term survival due to better radicality compared with left resections [13]. However, conflicting results have been reported, in which there were no significant differences in outcomes by lesion side in patients receiving curative surgery for Bismuth type III HC [20-22]. Our data also showed no significant differences in DFS and OS, cancer staging, R0 resection rate, local recurrence, or systemic recurrence rate between $\mathrm{RH}$ and $\mathrm{LH}$ patients. However, the perioperative outcomes of LH showed more bile leakage and longer operation times. This might be due to the multiple bile duct openings of the right side of the liver. As Shimizu et al. [15] reported, the relationship of the right posterior sectional bile duct (RPSBD) and RPV is a crucial factor for bile duct anastomosis. If RPSBD runs cranially around the RPV (supraportal type), achieving a negative margin of the proximal bile duct and anastomosis can be difficult. So, if a surgeon selects $\mathrm{LH}$ for the treatment of $\mathrm{HC}$, a preoperative radiologic evaluation for the anatomy of the bile duct and portal vein relationship is very important. Also, in multivariate analysis, the major risk factors for recurrence were CA 19-9 > $400 \mathrm{U} / \mathrm{mL}$ and LN metastasis, and the factor affecting OS was CA 19-9 > $400 \mathrm{U} / \mathrm{mL}$ alone. So, in patients who have greater tumor burdens with higher CA 19-9 and the presence of LN metastasis, more precise preoperative evaluation is needed to achieve a negative margin of surgical resection.

Although this study included a relatively large sample size of 326 total operative HC cases, this study was based on retrospective data. Moreover, the subgroup populations were relatively small for the study. Thus, prospective randomized controlled trials should be conducted in the future.

In conclusion, LH had comparable oncologic outcomes to $\mathrm{RH}$ with lower occurrence of ascites and higher bile leakage rates. However, postoperative ascites was more notable complication than postoperative bile leakage, as ascites is correlated with postoperative liver function, and bile leakages were all minor complications and resolved spontaneously by conservative care in our study. Also, more operation time and transfusion in $\mathrm{LH}$ patients did not affect patient's outcome. For these reasons, we concluded, LH can be an alternative surgical option to RH, considering bile duct anatomy and tumor location.

\section{CONFLICTS OF INTEREST}

No potential conflict of interest relevant to this article was reported.

\section{REFERENCES}

1. Buettner S, van Vugt JLA, Gaspersz MP, Coelen RJS, Roos E, Labeur TA, et al. Survival after resection of perihilar cholangiocarcinoma in patients with lymph node metastases. HPB (Oxford) 2017; 19:735-40.

2. Kambakamba P, Linecker M, Slankamenac K, DeOliveira ML. Lymph node dissection in resectable perihilar cholangiocarcinoma: a systematic review. Am J Surg 2015;210:694-701.

3. Ito F, Agni R, Rettammel RJ, Been MJ, Cho CS, Mahvi DM, et al. Resection of hilar cholangiocarcinoma: concomitant liver resection decreases hepatic recurrence. Ann Surg 2008;248:273-9.
4. Mansour JC, Aloia TA, Crane $\mathrm{CH}$, Heimbach JK, Nagino M, Vauthey JN. Hilar cholangiocarcinoma: expert consensus statement. HPB (Oxford) 2015;17:691-9.

5. Groot Koerkamp B, Wiggers JK, Allen PJ, Besselink MG, Blumgart LH, Busch OR, et al. Recurrence rate and pattern of perihilar cholangiocarcinoma after cura- 
tive intent resection. J Am Coll Surg 2015; 221:1041-9.

6. Chen KJ, Yang FC, Qin YS, Jin J, Zheng SS. Assessment of clinical outcomes of advanced hilar cholangiocarcinoma. Hepatobiliary Pancreat Dis Int 2018;17:155-62.

7. Bhardwaj N, Garcea G, Dennison AR, Maddern GJ. The surgical management of Klatskin tumours: has anything changed in the last decade? World J Surg 2015:39: 2748-56.

8. Lee SG, Song GW, Hwang S, Ha TY, Moon DB, Jung DH, et al. Surgical treatment of hilar cholangiocarcinoma in the new era: the Asan experience. J Hepatobiliary Pancreat Sci 2010;17:476-89.

9. Nagino M, Kamiya J, Arai T, Nishio H, Ebata T, Nimura Y. "Anatomic" right hepatic trisectionectomy (extended right hepatectomy) with caudate lobectomy for hilar cholangiocarcinoma. Ann Surg 2006;243: 28-32.

10. Kawasaki S, Imamura H, Kobayashi A, Noike T, Miwa S, Miyagawa S. Results of surgical resection for patients with hilar bile duct cancer: application of extended hepatectomy after biliary drainage and hemihepatic portal vein embolization. Ann Surg 2003:238:84-92.

11. Ikeyama T, Nagino M, Oda K, Ebata T, Nishio H, Nimura Y. Surgical approach to bismuth Type I and II hilar cholangiocarcinomas: audit of 54 consecutive cases.
Ann Surg 2007:246:1052-7.

12. Ribero D, Zimmitti G, Aloia TA, Shindoh J, Fabio F, Amisano M, et al. Preoperative cholangitis and future liver remnant volume determine the risk of liver failure in patients undergoing resection for hilar cholangiocarcinoma. J Am Coll Surg 2016;223:87-97.

13. Ratti F, Cipriani F, Piozzi G, Catena M, Paganelli M, Aldrighetti L. Comparative analysis of left- versus right-sided resection in Klatskin tumor surgery: can lesion side be considered a prognostic factor? J Gastrointest Surg 2015;19:1324-33.

14. Ji GW, Zhu FP, Wang K, Jiao CY, Shao ZC, Li XC. Clinical implications of biliary confluence pattern for Bismuth-Corlette type IV hilar cholangiocarcinoma applied to hemihepatectomy. J Gastrointest Surg 2017;21:666-75.

15. Shimizu H, Sawada S, Kimura F, Yoshidome H, Ohtsuka M, Kato A, et al. Clinical significance of biliary vascular anatomy of the right liver for hilar cholangiocarcinoma applied to left hemihepatectomy. Ann Surg 2009:249:435-9.

16. Balzan S, Belghiti J, Farges O, Ogata S, Sauvanet A, Delefosse D, et al. The "5050 criteria" on postoperative day 5: an accurate predictor of liver failure and death after hepatectomy. Ann Surg 2005; 242:824-8.

17. Han IW, Jang JY, Kang MJ, Kwon W, Park
JW, Chang YR, et al. Role of resection for Bismuth type IV hilar cholangiocarcinoma and analysis of determining factors for curative resection. Ann Surg Treat Res 2014:87:87-93.

18. Hwang S, Lee SG, Ko GY, Kim BS, Sung KB, Kim $\mathrm{MH}$, et al. Sequential preoperative ipsilateral hepatic vein embolization after portal vein embolization to induce further liver regeneration in patients with hepatobiliary malignancy. Ann Surg 2009;249:608-16.

19. Yasuda Y, Larsen PN, Ishibashi T, Yamashita K, Toei H. Resection of hilar cholangiocarcinoma with left hepatectomy after pre-operative embolization of the proper hepatic artery. HPB (Oxford) 2010;12:147-52.

20. Lee Y, Choi D, Han S, Han IW, Heo JS, Choi SH. Comparison analysis of left-side versus right-side resection in bismuth type III hilar cholangiocarcinoma. Ann Hepatobiliary Pancreat Surg 2018;22:3508.

21. Nimura Y. Radical surgery of left-sided klatskin tumors. HPB (Oxford) 2008;10: 168-70.

22. Farid SG, White A, Khan N, Toogood GJ, Prasad KR, Lodge JP. Clinical outcomes of left hepatic trisectionectomy for hepatobiliary malignancy. Br J Surg 2016; 103:249-56. 